\title{
A metafísica circular de Schopenhauer e a imagem filosófica da esfera
}

\author{
The circular metaphysics of Schopenhauer and the philosophical \\ image of the sphere
}

Luan Corrêa da Silva

luanbettiol@gmail.com

(Universidade Federal do Paraná, Paraná, Brasil)

\begin{abstract}
Resumo: 0 objetivo geral deste artigo é defender a importância do círculo ou da esfera como recurso filosófico para a compreensão do pensamento de Schopenhauer. Inicialmente a imagem é apresentada a pretexto do que chamamos de círculo hermenêutico de Schopenhauer, o qual descreve uma circularidade metodológica característica de seu pensamento. Em seguida, a imagem ganha profundidade na forma esférica como recurso para compreensão da metafísica imanente. Por fim, a geometria euclidiana é contrastada com a geometria intuitiva, visando a fundamentação do uso de imagens na filosofia de Schopenhauer.
\end{abstract}

Palavras-chave: círculo; esfera; metafísica imanente; geometria; Schopenhauer.

\begin{abstract}
The purpose of this article is to defend the importance of the circle or sphere as a philosophical resource for understanding Schopenhauer's thought. Initially, the image is presented under the pretext of what we call the Schopenhauer's hermeneutic circle, describing a typical methodological circularity of his way of thinking. Then, the image gains depth in the spherical form as a resource to comprehend immanent metaphysics. Finally, the Euclidean geometry is contrasted by intuitive geometry, in order to reason about the imagery usage in Schopenhauer's philosophy.
\end{abstract}

Keywords: circle; sphere; immanent metaphysics; geometry; Schopenhauer.

\section{O círculo hermenêutico de 0 mundo como vontade e representação}

No prefácio da primeira edição de sua principal obra, publicada em 1818, Schopenhauer apresenta "a maneira como este livro deve ser lido para, assim, poder ser compreendido" e complementa: “o que deve ser comunicado por ele é um pensamento único" (ein einziger Gedanke). Um pensamento único, todavia, com “diferentes lados" (verschiedenen Seiten), tradicionalmente nomeados de Teoria do conhecimento, Metafísica, Ética e Estética. ${ }^{1} \mathrm{Na}$ apresentação de sua metodologia expositiva, o filósofo de 0 mundo como vontade e representação anuncia alguns aspectos que permanecerão vigentes em seus escritos tardios.

1 Schopenhauer também chama de Dianologia (Dianoiologie) ou Doutrina do conhecimento (Verstandeslehre), Metafísica da natureza (Metaphysik der Natur), Metafísica do belo (Metaphysik des Schönen) e Metafísica da ética (Metaphysik der Sitten) (Schopenhauer, 2010, pp.46-49). 
Em 1818, ele escreve:

Um SISTEMA DE PENSAMENTOS [System von Gedanken] tem sempre de possuir uma coesão arquitetônica, ou seja, uma tal em que uma parte sustenta continuamente a outra, e esta, por sua vez, não sustenta aquela, em que a pedra fundamental sustenta todas as partes, sem no entanto ser por elas sustentada, em que o tipo é sustentado, sem no entanto sustentar. Ao contrário, UM PENSAMENTO ÚNICO [ein einziger Gedanke], por mais abrangente que seja, guarda a mais perfeita unidade [Einheit]. Se, todavia, em vista de sua comunicação [Mittheilung], é decomposto em partes, então a coesão destas tem de ser, por sua vez, orgânica, isto é, uma tal em que cada parte tanto conserva o todo quanto é por ele conservada, nenhuma é a primeira ou a última, o todo ganha em clareza [Deutlichkeit] mediante cada parte, e a menor parte não pode ser plenamente compreendida [völlig verstanden] sem que o todo já o tenha sido previamente. - Um livro tem de ter, entrementes, uma primeira e uma última linha; nesse sentido, permanece sempre bastante dessemelhante a um organismo, por mais que se assemelhe a este em seu conteúdo. Consequentemente, forma [Form] e estofo [Stoff] estarão aqui em contradição. Sob tais circunstâncias, resulta facilmente que para penetrar na exposição destes pensamentos há apenas um conselho: LER O LIVRO DUAS VEZES, e em verdade a primeira vez com muita paciência, haurivel da crença voluntária e espontânea de que o começo pressupõe o fim quase tanto quanto o fim, o começo, e, precisamente dessa forma, cada parte anterior pressupõe quase tanto a posterior quanto esta aquela (Schopenhauer, 2015a, p.VIII). ${ }^{2}$

Neste importante trecho, Schopenhauer apresenta a sua conhecida contraposição à arquitetônica da Crítica da Razão Pura kantiana (cf. Kant, KrV A 832/ B 860). No pensamento único schopenhaueriano, a divisão do livro em quatro considerações visa tão somente facilitar sua exposição e apreensão, apesar da cronologia não the ser essencial. O conteúdo de seus temas, porém, "de forma alguma admite um progresso em linha reta, como o histórico" e, por isso, não apenas as partes do livro têm uma relação entre si, mas cada parte da obra está conectada a todas as outras e as pressupõe (Schopenhauer, 2015a, pp.330-1). A verticalidade arquitetônica é símbolo da linearidade e do progresso. Em um edifício, a parte mais profunda da fundação é a base da estrutura que se eleva, análogo a uma planta, em que a raiz precede e sustenta a corola. Especialmente na tradição moderna, a filosofia é ancorada na epistemologia ou teoria do conhecimento, também chamada de filosofia prima, a saber: a investigação sobre as faculdades de conhecimento, suas formas, leis, validade e limites (Schopenhauer, 2010, p.47). ${ }^{3}$ No idealismo kantiano, particularmente, a investigação acerca da realidade empírica está condicionada à investigação acerca dos limites do conhecimento humano, suas formas puras e categorias a priori.

2 Outras versões da mesma observação metodológica encontramos em Schopenhauer, cf. 2015a, pp.330-1 e 2001, p.8.

3 Um exemplo dessa hierarquia disciplinar é a conhecida classificação das ciências de Francis Bacon (Cf. 2007, p.136-45), na qual a filosofia prima é entendida enquanto "progenitor ou antepassado comum de todo conhecimento", "filosofia primitiva" que está "antes que os caminhos se dividam e separem", cujo objeto são os princípios e axiomas mais gerais das ciências. 
No sistema orgânico de pensamentos, porém, não há sobreposição de um tipo de conhecimento sobre o outro. Diferentemente, o sistema deve ser entendido em analogia com o organismo animal, em que cada órgão tanto sustenta e alimenta o organismo como é por ele alimentado. As partes se nutrem mutuamente e a vida do todo é conservada em um movimento autopoiético de alimentação e excreção. ${ }^{4}$ O objetivo de Schopenhauer é possibilitar a compreensão do todo a partir das partes e as partes a partir do todo, conectando a última página de seu livro à primeira. Por isso, a recomendação de "ler o livro duas vezes", uma regra metodológica associada ao que se poderia denominar de círculo hermenêutico de Schopenhauer. ${ }^{5}$

De fato, somente se adquire a intelecção adequada do pensamento apresentado n'O Mundo quando compreendemos as implicações éticas do princípio de razão suficiente, bem como a unidade entre metafísica e ética defendida pelo filósofo desde sua juventude. ${ }^{6}$ Em 1836, no seu escrito Sobre a vontade na natureza, ele diz:

Apenas aquela metafísica que já é ela mesma originalmente ética, sendo construída a partir de seu próprio material, a vontade, é o suporte efetivo e imediato da ética; razão pela qual eu teria muito mais direito de nomear a minha metafísica de "ética" do que Spinoza (...) Atrevo-me a dizer, no geral, que nunca houve um sistema filosófico que fosse tão completamente talhado de uma só peça como é o meu, sem lacunas ou remendos. Ele é, como eu disse no prefácio ao mesmo, o desdobramento de um único pensamento (Schopenhauer, 2013, p.210). ${ }^{7}$

Embora a imagem empírica do organismo seja mais rica em materialidade,

4 A esse respeito, ver o seguinte trecho: "visto que é a vontade única e indivisa - e justamente por isso inteiramente coerente consigo mesma (...) segue-se que o aparecimento da vontade, embora entre em cena numa diversidade de partes e estados, tem de mostrar novamente aquela unidade na concordância completa de tais partes e estados (...) Com isso conhecemos todas as diversas partes e funções do organismo como meios e fins recíprocos umas das outras, enquanto o organismo, nele mesmo, é o fim último de todas" (Schopenhauer, 2015a, pp.182-3).

50 "círculo hermenêutico", como passa a ser chamado na tradição da hermenêutica filosófica (Gadamer, 1999, p.400), é formulado no contexto da filologia alemã por Schleiermacher (1999, pp.46-7) na ideia de que "cada particular apenas pode ser compreendido por meio do todo e, portanto, toda explicação do particular pressupõe já a compreensão do todo". Schleiermacher foi professor de Schopenhauer e teve sua obra Hermenêutica e crítica (Hermeneutik und Kritik) postumamente publicada em 1838. Nesta obra (1998, pp.5ss), a hermenêutica é denominada de arte da compreensão (Kunst des Verstehens), enquanto técnica de interpretação e exegese de textos. Alguns intérpretes de Schopenhauer exploram a chave de leitura hermenêutica. Sandro Barbera (2004, pp.73-6) relaciona a metafísica de Schopenhauer a uma "hermenêutica da experiência" (Herméneutique de l'expérience), Rüdiger Safranski (2011, p.391) propõe a expressão "hermenêutica da existência" (Daseinshermeneutik) em sentido semelhante e Ruy de Carvalho (2012, pp.227-39) defende uma "hermenêutica da Representação".

6 Em 1813, ao finalizar a redação de sua tese doutoral, a Dissertação, Schopenhauer escreve: "Sob minhas mãos e muito mais dentro de meu espírito, está crescendo uma obra, uma filosofia que deverá transformar a ética e a metafísica em uma única disciplina" (Safranski, 2011, p.273; Schopenhauer, 1985, I, p.55).

7 Nos seus Fragmentos para a história da filosofia (1851), ele repete: “Praticamente não há sistema filosófico tão simples e composto de tão poucos elementos quanto o meu. Por isso, ele pode ser facilmente visto e compreendido com um só olhar. Em última instância isso se deve à unidade completa e à concordância de seus pensamentos fundamentais" (Schopenhauer, 2007, p.186). 
a imagem abstrata e simples de um círculo parece ilustrar melhor essa unidade de pensamento pretendida por Schopenhauer. As tradicionais e verticais divisões temáticas da filosofia dão lugar à circularidade que conduz ao ponto central. Podemos representar a divisão dos livros I (Dianologia), Il (Metafísica da natureza), III (Metafísica do belo) e IV (Metafísica da ética) de 0 mundo como vontade e representação do seguinte modo (fig. 1):

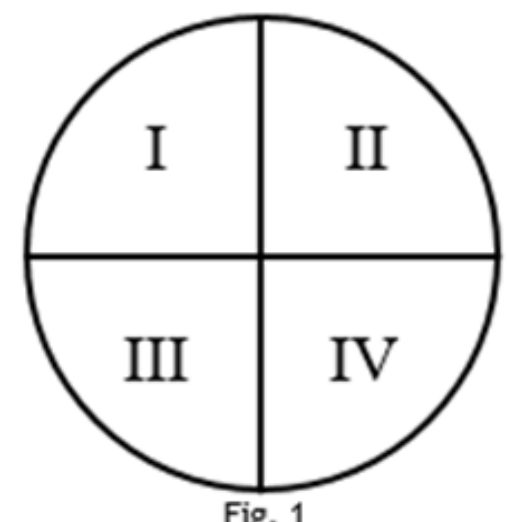

Fig. 1

A entrada circular do pensamento de Schopenhauer também é descrita na imagem empírica de "Tebas de cem portas", apresentada no primeiro prefácio de Os dois problemas fundamentais da ética (1840): "Quando chegar o tempo em que eu serei lido, verão que a minha filosofia é como a Tebas de cem portas: é possível entrar a partir de todos os lados e, através de cada um deles, chegar por um caminho direto até o ponto central" (Schopenhauer, 1942, III, p.434).

Além da estreita conexão entre os âmbitos de conhecimento do mundo, ao centro, a apresentação circular do sistema schopenhaueriano também conserva a especificidade de cada uma das perspectivas, mais à periferia. A variedade de temas da filosofia pode ser contemplada na circunferência, enquanto a centralidade da tese principal é preservada. Nesse sentido, pode-se passear pelos diferentes temas das ciências, das artes e da sociedade sem fazer perder de vista o pressuposto metafísico da unidade metafísica da vontade em meio à diversidade de suas manifestações empíricas, mesmo que, por vezes, esse passeio pareça ir demasiado longe. ${ }^{8}$

\section{A metafísica da esfera}

A circularidade do sistema schopenhaueriano serve de modelo metodológico da exposição de $O$ mundo como vontade e representação, conforme dissemos.

8 Notadamente nos Aforismos para sabedoria de vida, em que o próprio Schopenhauer diz ter se desviado totalmente (gänzlich abgehn) do "ponto de vista superior, ético-metafísico" (cf. Schopenhauer, 2002, pp.1-2). A esse respeito, ver Debona, 2020, especialmente pp.169-79. 
Mas esse modelo metodológico torna-se ainda mais compreensível quando essa circularidade é representada nos termos volumétricos de uma esfera. Com a imagem da esfera, avançamos para uma explicação não apenas metodológica d'O Mundo, mas, sobretudo, substantiva. Permite-nos visualizar a relação entre microcosmo e macrocosmo, entre a experiência interna e externa, ou, em outros termos, entre o uno e o múltiplo.

No segundo volume d'O Mundo, Capítulo 17, Schopenhauer trata da distinção entre a investigação metafísica e a física pela diferença entre a "casca" e o "núcleo". Segundo ele, a explicação física ou naturalista "jamais adquire um conhecimento cúbico por mais vasta que seja a sua ampliação", restringe-se à aparência, à "casca da natureza" (Schaale der Natur) e nenhum progresso the é possível. Assim, "mesmo se alguém explorasse todos os planetas de todas as estrelas fixas", nenhum passo poderia dar em direção ao centro. Tampouco o conhecimento microscópico pode oferecer um conhecimento cúbico ou volumétrico da aparência, restando aos "bisbilhoteiros da natureza" apenas investigarem "os parasitas dos parasitas" na superfície. Contrariamente, a metafísica se dirige ao "núcleo da natureza” (Kern der Natur), muito embora isso signifique, também, ter de abandonar o seguro lastro empírico do cientista natural; pois quanto mais completo, universal e fundamental é o conhecimento, tanto mais enigmático se apresenta para a nossa compreensão (Schopenhauer, 2015b, p.216). Em direção ao núcleo da experiência, a metafísica encontra um ponto de contato entre microcosmo e macrocosmo, a passagem (Übergang) do domínio da aparência ao da coisa em si encontrada na interioridade do corpo.

Desde os tempos mais antigos, falou-se do ser humano como um microcosmo. Eu inverti a proposição e demonstrei o mundo como um macroantropo; já que vontade e representação esgotam o ser do mundo e do humano. Manifestamente, é mais correto ensinar a entender o mundo a partir do humano, que o humano a partir do mundo: pois, a partir do que é imediatamente dado, logo, a partir da consciência de si, temos de explicar o que é mediatamente dado, logo, a intuição exterior; não o inverso (idem, p.766).

Com recurso à herança do idealismo crítico kantiano, Schopenhauer afirma vigorosamente sua metafísica imanente, na convicção de ter encontrado por uma via legítima - não inviabilizada pela filosofia crítica - a estreita passagem para a superação do idealismo transcendental. A metafísica imanente herda do empirismo britânico o respeito ao rigoroso tribunal da experiência, todavia, o filósofo se orgulha por ter encontrado na direção oposta da experiência empírica a chave para a solução do enigma dos antigos. É na interioridade dos impulsos e desejos em que é possível reconhecer a identidade metafísica da vontade. O desafio está na compreensão da interação entre esses dois domínios, algo que é muito bem expresso na "grande 
doutrina hèn kaí pan (Uno e tudo)" (cf. Schopenhauer, 2015b, pp.383, 766; 2001, pp.210-24). A sabedoria dos antigos converge na proposição o problema fundamental da metafísica: como da unidade devém a multiplicidade? Ou, como a essência é, ao mesmo tempo, aparência? Nos termos da filosofia schopenhaueriana, essa questão expressa a consciência de que por detrás de "milhões de figuras infinitamente variadas" expostas no "mais multicolorido e mais barroco espetáculo" reside uma única essência idêntica. Esta "se esconde tão densamente velada atrás de todas aquelas máscaras" que não se reconhece e, em razão disso, "trata a si mesma de maneira rude" (Schopenhauer, 2015b, p.383).

0 dualismo metafísico entre vontade e representação contrapõe essa unidade conciliadora com a natureza belicosa da vontade apreendida na perspectiva imanente do egoísmo. Cada uma das partes da filosofia de Schopenhauer não faz mais que explicitar, a partir de um registro determinado, esse conflito. Há, em razão disso, uma certa tensão entre o registro imanente da metafísica e o domínio transcendente da especulação. Se, por um lado, Schopenhauer advoga em favor da experiência (Erfahrung) contra o dogmatismo transcendente da especulação filosófica, é verdade que ele também reconhece ter de recorrer ao expediente transcendente da explicação para compreender essa interação.

Diante do tema da unidade metafísica, vê-se a necessidade de um "desvio" (Umwege) em relação à sua exposição imanente, na medida em que as imperfeições do intelecto ligadas à sua índole condicionante impossibilitam uma intelecção da unidade incondicional da coisa em si (cf. idem, p.348). Precisamente em virtude desse contingente explicativo associado a uma limitação da razão abstrata, faz-se necessário o recurso a artifícios próprios da linguagem poética - metáforas, parábolas, imagens etc. - ainda que com elas se possa apenas quadam prodire tenus, avançar até certo ponto (idem, p.389). 0 sobrevoo da explicação transcendente, afastada da experiência, visa articular oposições incompreensíveis ao intelecto: a unidade do causal com o intencional, do necessário com o livre, em suma, da aparência com a essência. ${ }^{9}$ Com esse propósito, Schopenhauer formula na eloquente imagem da esfera um conteúdo silenciado no discurso racional. Embora não possa lançar luz plena (volles Licht) para a intelecção do problema, mas apenas um lampejo (Schimmer), a imagem da esfera torna visível num só golpe uma série de complexas interações do mundo. Esta imagem é apresentada ao fim do Capítulo 25 do segundo volume d'O Mundo (1841):

9 Nessa perspectiva, talvez coubesse a essa filosofia a mesma definição de Jean Brun conferida à filosofia de Plotino em referência a H. Ch. Puech: uma "mística da imanência nos quadros de uma metafísica da transcendência" (mystique de l'immanence dans le cadres d'une métaphysique de la transcendance) (Brun, 1988, p.28). Apesar de recorrer à explicação transcendente, isso não implica a defesa de um fundamento ontológico transcendente. Ver, principalmente, Cacciola, 1994, pp.137-38. 
Assim como na esfera a superfície nasce onde os raios terminam e rompem, também a consciência só é possível onde a essência em si desemboca na aparência, através de cujas formas é possível a individualidade separada, na qual repousa a consciência, que justamente por isso está limitada às aparências. Por conseguinte, todo o distinto e bem compreensível de nossa consciência encontra-se sempre na direção do exterior, sobre essa superfície da esfera. Por outro lado, assim que daí nos afastamos por completo, a consciência nos abandona, - no sono, na morte, em certa medida também no fazer-efeito magnético ou mágico: pois todos estes passam pelo centro. Mas precisamente porque a consciência distinta das coisas, como condicionada pela superfície da esfera, não está dirigida para o centro, decerto conhece os outros indivíduos como da mesma espécie, mas não como idênticos, que é o que de fato eles são em si. A imortalidade do indivíduo poderia ser comparada ao escape de um ponto da superfície pela tangente; a imortalidade de toda a aparência, devido à eternidade da essência em si, poderia ser comparada ao retorno desse ponto, pelo raio, em direção ao centro, do qual a superfície é mera extensão. A vontade como coisa em si está inteira e indivisa em cada ser, assim como o centro é parte integrante de cada um dos raios: enquanto o extremo periférico do raio está na mais rápida revolução com a superfície, que representa o tempo e o seu conteúdo, já o outro extremo, no centro, sede da eternidade, permanece no mais profundo repouso, porque o centro é o ponto cuja metade ascendente não difere da descendente (idem, pp.391-2).

O parentesco interior (innere Verwandtschaft) das aparências e a difícil relação entre unidade essencial e multiplicidade aparente são perfeitamente ilustrados pela forma esférica. Uma das vantagens da esfera em relação à forma simples do círculo reside na sua dimensão cósmica que permite uma melhor suspensão das referências espaciais: acima, abaixo, à direita e à esquerda. Na figura seguinte (fig. 2), a unidade essencial da vontade é representada pelo ponto hipotético ao centro, em oposição ao pontilhado multidirecional da superfície.

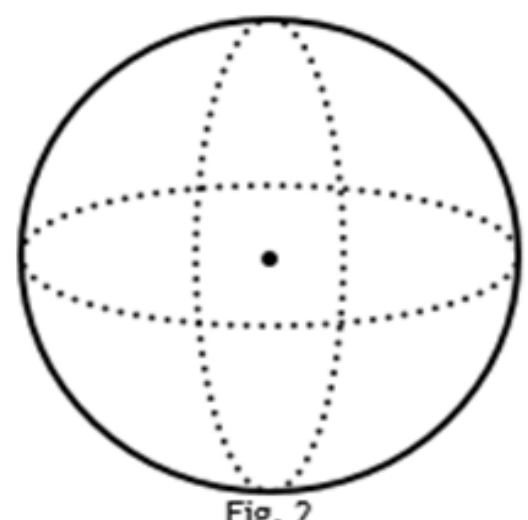

Fig. 2 
Essa unidade (Einheit) essencial deve ser entendida não como parte da pluralidade, mas alheia a ela. Ou seja, não como uma unidade aritmética, mas enquanto a própria negação da divisão matemática. A vontade "é uma (er ist Eines) como aquilo que se encontra fora do tempo e do espaço, exterior ao principium individuationis, isto é, da possível pluralidade" (Schopenhauer, 2015a, p.132). De acordo com essa imagem, somente a superfície pode ser quantificada. A explicação transcendental para isso encontramos no quarto capítulo da Dissertação de 1813: tempo é a forma do sentido interno de representação, portanto, tem realidade apenas subjetiva, nunca em si mesma.

Resulta que a temporalidade do mundo e das existências particulares sejam ilusórias se contrastadas com a eternidade imóvel da vontade em si, tema desenvolvido amplamente no capítulo do segundo volume d'O Mundo, intitulado "Sobre a morte e sua relação com a indestrutibilidade de nosso ser em si" (Ueber den Tod und sein Verhältniß zur Unzerstörbarkeit unsers Wesens an sich). Neste capítulo, a imagem do círculo é "o autêntico símbolo da natureza", é o "esquema do retorno" (Schema der Wiederkehr) (Schopenhauer, 2015b, p.571). Uma apreensão objetiva dos acontecimentos imediatos da vida, nessa perspectiva, permitiria ver com "um único olhar" o "centro da roda do tempo" (idem, p.576). Assim, toda mudança na série dos nascimentos e mortes seria vista como a vibração continuada que descreve a forma de um fuso, ou a faísca que girada rapidamente aparenta o desenho de um círculo permanente. A morte nos seria apenas aparente e nosso verdadeiro ser indestrutível, pois "para o núcleo da vida (...) a morte não é um obstáculo" (idem, p.578).

Outra imagem utilizada por Schopenhauer é a roda extraída do mito grego de íxion, enquanto símbolo da condição de perpétua servidão e sofrimentos que nos é imposta. Semelhantes a Íxion, os indivíduos estão condenados à carência imposta pelas necessidades nunca satisfeitas, pois, a cada desejo satisfeito, dez novos surgem esperando satisfação. A liberdade do sujeito puro proporcionada momentaneamente pela experiência estética representa o repouso da roda (Schopenhauer, 2015a, p.227). A metempsicose platônica ou imortalidade do indivíduo seria análoga ao escape de um ponto da circunferência pela tangente (fig. 3). Já a palingenesía (Palingenesie, Pali+genesia), como Schopenhauer prefere denominar a indestrutibilidade não do indivíduo, mas da essência (cf. Schopenhauer, 2015b, p.600), pode ser representada pelo retorno da circunferência ao centro pelo raio (fig. 4): 


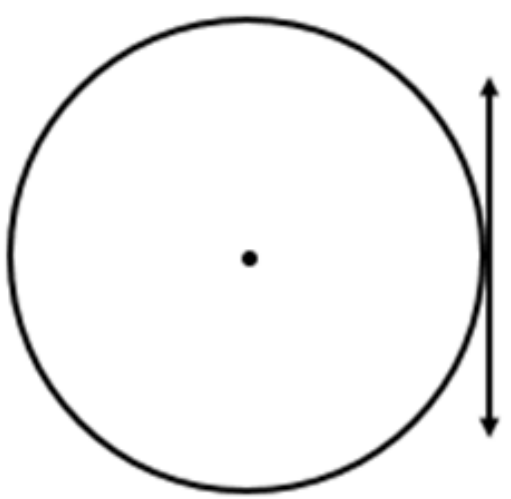

Fig.3

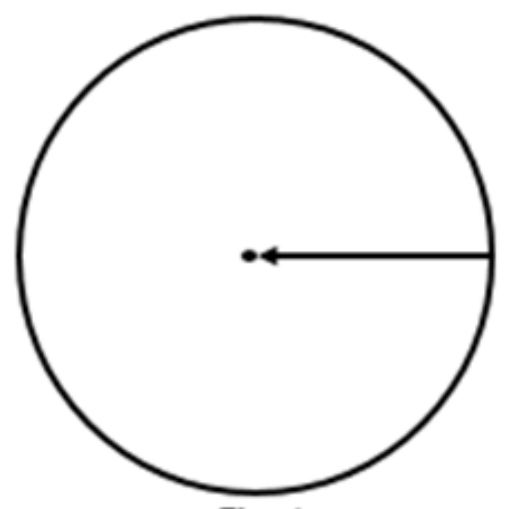

Fig. 4

Schopenhauer deriva de sua concepção idealista do tempo sua concepção da história (Geschichte), na medida em que esta aborda o tempo em sua perspectiva macroscópica ou social. A narrativa histórica é, assim, igualmente ilusória e aparente, inferior, portanto, à poesia (cf. Schopenhauer, 2015a, pp.282-3).

Assim como o círculo de uma polegada de diâmetro possui exatamente as mesmas características do círculo de quarenta milhões de polegadas, assim também os acontecimentos e a história de uma aldeia são, no essencial, os mesmos que os de um reino (idem, p.286).

O movimento de revolução de um círculo ou esfera circunscreve-se sempre em torno de um eixo central imóvel. Podemos ter experiência disso quando nos imaginamos em cima de um disco em movimento. Quanto mais próximos da extremidade do disco, mais rapidamente giramos; mas, quando nos aproximamos do centro, notamos que a velocidade de rotação reduz drasticamente, tendendo ao repouso. 0 ponto hipotético mais central corresponderia ao repouso absoluto (fig. 5).

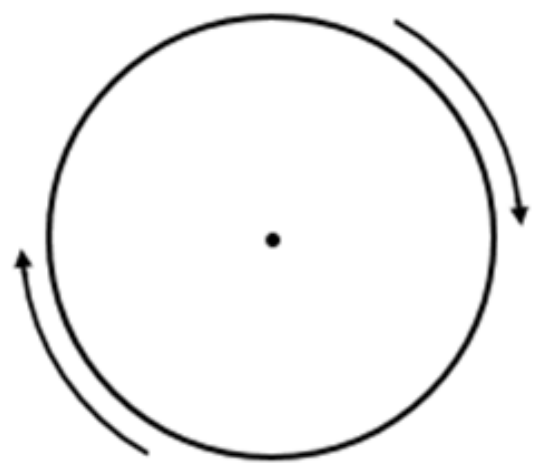

Fig. 5 
Com a imagem da esfera também conseguimos visualizar os diversos graus de consciência da realidade, do mais claro e distinto ao mais obscuro e inconsciente (cf. Schopenhauer, 2015b, p.339); em outras palavras: da nítida luz do entendimento até os obscuros movimentos internos da vontade reunidos sob a rubrica do sentimento, Gefühl (Schopenhauer, 2015a, §11; Silva, 2020). Em termos psicológicos, a consciência empírica, ou "consciência das outras coisas" (Bewußtseyn anderer Dinge), se distingue da "consciência de si" (Selbstbewußtseyn) na perspectiva de sua mirada, embora se trate da mesma consciência: no primeiro caso, ela é dirigida para o sentido exterior do corpo e, no segundo, para o interior (cf. Schopenhauer, 2019, pp.311-5; 2015b, pp.244-5). Essa diferença no direcionamento do conhecimento determina a possibilidade da passagem do mundo dos fenômenos para o mundo do querer e, com isso, resulta na compreensão da identidade metafísica (metaphysische Identität) em oposição à identidade numérica (numerische Identität).

Podemos dizer que o centro hipotético da esfera, inefável, representa o marco-limite do conhecimento positivo e da linguagem que Schopenhauer tematizou no último parágrafo d'O Mundo, e que é resumido de maneira aforismática na sétima proposição do Tractatus de Wittgenstein: "sobre o que não se pode dizer deve-se calar" (Wovon man nicht sprechen kann, darüber muss man schweigen) (Wittgenstein, 1968, p.129). Para encontrar esse limite, portanto, basta que nos afastemos da superfície da esfera e adentremos no seu interior, movimento que lembra de maneira invertida a clássica alegoria da caverna de Platão. Essa inversão é operada por Plotino, em cujas Enéadas encontramos uma formulação da imagem do círculo muito similar àquela apresentada por Schopenhauer:

\begin{abstract}
A esta primeira [coisas divididas e separáveis] é contraposta uma segunda espécie de ser que de modo algum admite divisão, é indivisa e indivisível, não admite extensão alguma, nem sequer em nosso pensamento; não necessita de lugar, e não se encontra em nenhum outro ser, nem em parte, nem totalmente. Monta, por assim dizer, em todos os seres ao mesmo tempo, não para servir deles como substância, mas porque as outras coisas não podem e nem querem existir sem ela. É uma essência sempre idêntica a si mesma, comum a tudo o que decorre dela; como o centro de um círculo, no qual todas as linhas que se estendem para a circunferência estão ligadas e, não obstante o centro permanecer imóvel, derivam dele a sua origem e o seu ser, participando do centro, ponto indivisível que é o seu princípio; mas, uma vez que estão vinculadas a ele, procedem dele (Plotino, 1966, IV, pp.8-11). ${ }^{10}$
\end{abstract}

Na metafísica do Uno de Plotino, o Uno não é algo, qualidade, quantidade, nem intelecto (noûs) ou alma (psykhé), não se move, não está em um lugar no tempo e nem no espaço, não possui uma forma, em suma, "é falso até mesmo dizer que é um" (Plotino, 1966, V, pp.140-1). Para Plotino, como para Schopenhauer, a unidade

10 Há diversas ocorrências da imagem do círculo e, também, da esfera nas Enéadas de Plotino. Cf. Plotino, 1966, I, pp.270-1; idem, III, pp.386-9; idem, IV, pp.8-11; idem, V, pp.48-51; idem, VI, pp.334-9. 
essencial possui uma positividade real que apenas negativamente pode ser expressa na linguagem. ${ }^{11}$

\section{A geometria intuitiva de Schopenhauer}

É conhecida a inscrição no pórtico da Academia platônica que dizia "Quem não é geômetra não entre!” (cf. Cornelli; Coelho, 2007). Na República, a abstração geométrica (o mesmo vale para a aritmética) possibilita um primeiro estágio de pura abstração do pensamento (diánoia), em que se parte de formas visíveis para o raciocínio das formas elas mesmas, independente de seus exemplares. Está-se a um passo do inteligível das Ideias. Por isso o esforço de Sócrates, no diálogo Mênon, em conduzir um escravo sem educação matemática a operar deduções geométricas. Com efeito, o raciocínio matemático é, aqui, o protótipo da dialética.

É assim que Schopenhauer interpreta a inscrição na Academia de Platão, uma exigência cujo pressuposto é o da abstração geométrica entendida como propedêutica das abstrações eidéticas, isto é, um caminho facilitado para a compreensão das Ideias. Com esse "exercício preliminar" (Vorübung), diz o filósofo alemão, “o espírito do aluno acostumava-se com a ocupação de objetos incorpóreos, após até ali ter lidado na vida prática apenas com coisas corpóreas" (Schopenhauer, 2015b, p.158). Há, por parte de Schopenhauer, um reconhecimento em Platão de uma apreensão intuitiva da geometria capaz de conduzir o espírito, como um trampolim, a uma compreensão de outra ordem: “é preciso antes de tudo eliminar o preconceito de que a verdade demonstrada possui alguma vantagem sobre a verdade conhecida intuitivamente" (Schopenhauer, 2015a, p.87).

Geometria e aritmética situam-se, no pensamento de Schopenhauer, no âmbito da doutrina da razão de ser (Lehre vom Grunde des Seyns), isto é, são ciências puras a priori do espaço e do tempo. Dizem respeito, portanto, ao conhecimento acerca das relações puras do tempo e do espaço típicas da terceira figura (Gestaltung) do princípio de razão suficiente (Satzes vom zureichenden Grunde). O princípio de razão se comporta de maneira diferente em cada uma de suas figuras, regentes das interações empíricas (devir), do conhecimento abstrato da razão (conhecer), das intuições matemáticas (ser) e da motivação (agir). Mas "nenhuma de suas figuras tem prerrogativa sobre as outras" (idem, p.87). O princípio de razão de ser constitui representações de tipo intuitivo puro, cujo correlato subjetivo é a sensibilidade (Sinnlichkeit) e não o entendimento (Verstand). No âmbito puro, as

11 No fragmento póstumo 51 de 1830, Cogitata I, Schopenhauer reconhece o parentesco de sua descrição com a de Plotino (1985, IV, pp.22-3): "essas profundezas da filosofia, esses limites extremos de nosso pensamento e investigação só podem ser expressos aqui por imagem e comparação, como é a esfera (...) Esta consideração tem semelhança com a de Plotino, a qual não me era conhecida no momento de minha escrita". Na sequência a essa anotação, reproduz uma parte do mesmo trecho das Enéadas citado neste artigo. 
relações próprias das matemáticas não se confundem com as elaborações complexas desenvolvidas a partir delas e, em razão disso, geometria e aritmética não seriam ciências demonstrativas, mas apenas intuitivas. Reside nessa concepção intuitiva do conhecimento geométrico a principal divergência em relação a Euclides.

Segundo Schopenhauer, os Elementos de Euclides misturam teoremas assentados propriamente em intuições (Anschauungen) geométricas com outros que são já desdobramentos refletidos e secundários dessas intuições. Esses desdobramentos são as demonstrações, um tipo de raciocínio relativo a outra figura do princípio de razão suficiente cuja faculdade correspondente é a da razão (Vernunft), o princípio de razão do conhecer. Por esse motivo, o filósofo efetua uma limpeza nos Elementos semelhante àquela realizada na tábua de categorias kantiana. Dos doze teoremas do matemático, apenas o nono, o décimo primeiro e o décimo segundo teriam origem na intuição (Schopenhauer, 2019, p.299). De acordo com essa concepção, a prova geométrica deve guardar sua natureza intuitiva, na medida em que, por exemplo, é muito mais fácil compreender a formulação do teorema de Pitágoras mediante sua representação visual (fig. 6 e fig. 7) $)^{12}$ do que pela fórmula $a^{2}+b^{2}=c^{2}$.

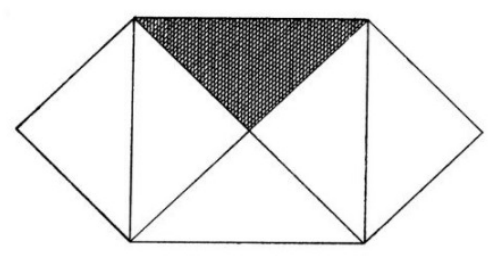

Fig. 6

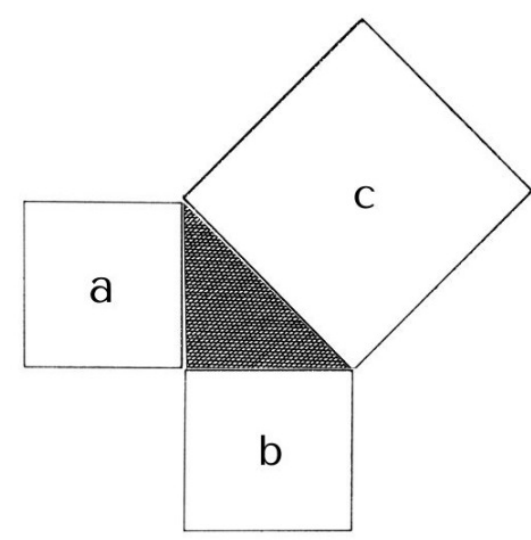

Fig.7

As duas figuras nos permitem visualizar o conteúdo da equação, isto é: de que a área do quadrado "a" somada com a área do quadrado "b" equivale à área do quadrado "c".

Ao explicar o teorema de Pitágoras por intermédio de um expediente imagético e não conceitual-demonstrativo, Schopenhauer pretende mostrar em que medida o conhecimento das relações mais puras da geometria é possibilitado pela mera intuição visual, tal como no diálogo Mênon de Platão (1980, pp.258-64). Com efeito,

12 Para melhor compreensão, desdobrei a figura 6 na figura 7. A figura 6 é originalmente publicada em Sobre a quadrúplice raiz do princípio de razão suficiente (Schopenhauer, 2019, p.352). 
enquanto a prova mediante a razão do conhecer (Erkenntnißgrund) produz apenas a convictio, convicção, a prova mediante a razão de ser, a saber, a intuição pura $a$ priori, proporciona a cognitio, cognição (Schopenhauer, 2019, p.301). A dificuldade em compreender a natureza intuitiva dos objetos matemáticos surge da confusão entre dois modelos de compreensão distintos: o que deriva as relações matemáticas dos axiomas e princípios, e o que compreende o caráter a priori das relações matemáticas, para as quais os axiomas e princípios já são deliberações artificiais. A geometria conceitual de Euclides se contrapõe, pois, à geometria intuitiva de Schopenhauer. ${ }^{13}$

A concepção schopenhaueriana da geometria é um instrumento teórico que possibilita a fundamentação do uso de imagens para a compreensão filosófica. Ora, do mesmo modo que os artifícios poéticos da linguagem auxiliam a compreensão das intuições filosóficas, também as imagens intuitivas da geometria lhes são um importante auxílio, permitindo-nos uma compreensão ainda mais pura de seus significados. Justamente porque a intuição (Anschauung, Intuition) possui precedência em relação à reflexão (Reflexion), as imagens são primárias em relação aos conceitos, e Schopenhauer é incansável na defesa do conhecimento intuitivo.

\section{Considerações finais}

Nossa interpretação reivindica a importância da imagem circular ou esférica para a filosofia de Schopenhauer. O sentido dessa imagem extrapola a pura significação geométrica, apesar de encontrar nela a sua condição de possibilidade. O caminho intuitivo do conhecimento, contrário ao dedutivo racional, permite-nos transformar a mera forma geométrica em um modelo de articulação de conhecimentos metafísicos, inapreensíveis adequadamente pela linguagem conceitual abstrata. A forma da esfera, como vimos, é a mais eloquente delas.

Em defesa dessa hipótese, iniciamos o presente artigo pela apresentação circular do pensamento para que compreendêssemos as diretrizes hermenêuticas indicadas por Schopenhauer no prefácio de 0 mundo como vontade e representação. Em seguida, conectamos esses aspectos metodológicos aos fundamentos teóricos dessa obra e apresentamos o modelo esférico da metafísica imanente. Por fim, reconectamos o ganho substantivo dessa imagem ao pressuposto intuitivo da matemática, por meio da defesa de uma geometria intuitiva. 0 principal resultado dessa interpretação é o de permitir a fundamentação teórica ampla e estrita do uso de imagens como instrumento compreensivo da metafísica imanente de Schopenhauer.

13 No que diz respeito ao método euclidiano, Schopenhauer complementa: "É em geral o método analítico o que desejo para a exposição da matemática, em vez do sintético usado por Euclides" (Schopenhauer, 2015a, p.86). Para um aprofundamento acerca da concepção filosófica de Schopenhauer acerca das matemáticas, bem como o contexto do debate, ver o recém publicado Language, Logic, and Mathematics in Schopenhauer (Lemanski, 2020). 


\section{Referências}

Bacon, F. (2007). O progresso do conhecimento. Tradução, apresentação e notas de Raul Fiker. São Paulo, SP: Editora UNESP.

Barbera, S. (2004). Une philosophie du conflit. Études sur Schopenhauer. Paris : Presses Universitaires de France (PUF).

Brun, J. (1988). O Neoplatonismo. Tradução de José Freire Colaço. Lisboa: Edições 70.

Cacciola, M.L. (1994). Schopenhauer e a Questão do Dogmatismo. São Paulo, SP: Editora da Universidade de São Paulo.

Cornelli, G.; Coelho, M.C. (2007). “Quem não é geômetra não entre!” Geometria, Filosofia e Platonismo. Kriterion: Revista de Filosofia, 48 (116), 417-435. DOI: https://doi.org/10.1590/S0100-512X2007000200009

Carvalho, R. (2012). Schopenhauer: Cosmologia como hermenêutica da Representação. Ethic@ - An international Journal for Moral Philosophy, 11 (2), 227-239. DOI: https://doi.org/10.5007/1677-2954.2012v11nesp1p227

Debona, V. (2020). A outra face do pessimismo: caráter, ação e sabedoria de vida em Schopenhauer. São Paulo, SP: Edições Loyola.

Gadamer, H-G. (1997). Verdade e método. Tradução de Flávio Paulo Meurer. Petrópolis, RJ: Vozes.

Kant, I. (1988). Prolegômenos a toda metafísica futura que queira se apresentar como ciência. Tradução de Artur Morão. Lisboa: Edições 70.

Kant, I. (2001). Crítica da razão pura. Tradução de Manuela Pinto dos Santos e Alexandre Fradique Morujão. $5^{\mathrm{a}}$ ed. Lisboa: Fundação Calouste Gulbenkian.

Platão. (1980). Apologia de Sócrates, Críton, Mênon, Hípias Menor e outros. In Nunes, B. (org.), Diálogos Platão (vols. 1-2). Tradução de Carlos Alberto Nunes. Belém, PA: Universidade Federal do Pará.

Lemanski, J. (ed.). (2020). Language, Logic, and Mathematics in Schopenhauer. Basel, Schweiz: Birkhäuser.

Plotino. (1966). Enneads (Vols. I-VII). Translated by Armstrong, A. H. Loeb Classical Library 440. Cambridge, MA: Harvard University Press.

Safranski. R. (2011). Schopenhauer e os anos mais selvagens da filosofia: uma biografia. Tradução de William Lagos. São Paulo, SP: Geração Editorial.

Schleiermacher, F. (1998). Hermeneutics and criticism and other writings. Translated and edited by Andrew Bowie. Cambridge: Cambridge University Press.

Schleiermacher, F. (1999). Hermenêutica - Arte e técnica da interpretação. Tradução e apresentação de Celso Reni Braida. Petrópolis, RJ: Vozes.

Schopenhauer, A. (1942). Sämtliche Werke. In Deussen, P. (Hrsg.). München: Piper Verlag, 16 Bände.

Schopenhauer, A. (1985). Die Manuskripte der Jahre 1830-1852. In Hübscher, A. (Hrsg.), Der handschrifliche Nachlaß (Band IV, 1). München: DTV, 5 Bände.

Schopenhauer, A. (2001). Sobre o fundamento da moral. Tradução de Maria Lúcia Mello Oliveira Cacciola. $2^{a}$ ed. São Paulo, SP: Martins Fontes. 
Schopenhauer, A. (2002). Aforismos para a sabedoria de vida. Tradução, prefácio e notas de Jair Barboza, revisão da tradução de Karina Jannini. São Paulo, SP: Martins Fontes.

Schopenhauer, A. (2007). Fragmentos sobre a história da filosofia; precedido de Esboço de uma história da doutrina do ideal e do real. Tradução de Karina Jannini e prefácio de Jair Barboza. São Paulo, SP: Martins Fontes.

Schopenhauer, A. (2010). Sobre a filosofia e seu método. Organização e tradução Flamarion C. Ramos. São Paulo, SP: Hedra.

Schopenhauer, A. (2013). Sobre a vontade na natureza. Tradução, prefácio e notas de Gabriel Valladão Silva. Porto Alegre, RS: L\&PM.

Schopenhauer, A. (2015a). O mundo como vontade e como representação, $1^{\circ}$ tomo. Tradução, apresentação, notas e índices de Jair Barboza. $2^{a}$ ed. São Paulo, SP: Editora Unesp.

Schopenhauer, A. (2015b). O mundo como vontade e como representação, segundo tomo: Suplementos aos quatro livros do primeiro tomo. Tradução, apresentação, notas e índices de Jair Barboza. $1^{\text {a }}$ ed. São Paulo, SP: Editora Unesp.

Schopenhauer, A. (2019). Sobre a quadrúplice raiz do princípio de razão suficiente: Uma dissertação filosófica. Tradução de Oswaldo Giacoia Junior e Gabriel Valladão Silva. Campinas, SP: Editora da Unicamp.

Silva, L. (2018). A unidade ética em "O mundo como vontade e como representação" de Schopenhauer. Voluntas: Revista Internacional de Filosofia, 9 (2), 4-15. DOI: https: //doi.org/10.5902/2179378635344

Silva, L. (2020). Sobre a negatividade conceitual do sentimento ou a filosofia schopenhaueriana da linguagem. Revista Trans/form/ação, 43 (1), 173-188.

Wittgenstein, L. (1968). Tractatus Logico-Philosophicus. Tradução e apresentação de José Arthur Gianotti. São Paulo, SP: Companhia Editora Nacional - Editora da Universidade de São Paulo. 